\title{
Selective Precipitation of Metal Oxalates from Lithium Ion Battery Leach Solutions
}

\author{
Eva Gerold *, Stefan Luidold and Helmut Antrekowitsch \\ Chair of Nonferrous Metallurgy of Montanuniversitaet Leoben, 8700 Leoben, Austria; \\ stefan.luidold@unileoben.ac.at (S.L.); helmut.antrekowitsch@unileoben.ac.at (H.A.) \\ * Correspondence: eva.gerold@unileoben.ac.at; Tel.: +43-3842-402-5207
}

\begin{abstract}
The separation of cobalt and nickel from sulfatic leach liquors of spent lithium-ion batteries is described in this paper. In addition to the base metals (e.g., cobalt and nickel), components such as manganese and lithium are also present in such leach liquors. The co-precipitation of these contaminants can be prevented during leach liquor processing by selective precipitation. For the recovery of a cobalt-nickel mixed material, oxalic acid serves as a suitable reagent. For the optimization of the precipitation retention time and yield, the dependence of the oxalic acid addition must be taken into account. In addition to efficiency, attention must also be given to the purity of the product. After this procedure, further processing of the products by calcination into oxides leads to better marketability. A series of experiments confirms the suitability of oxalic acid for precipitation of cobalt and nickel as a mixed oxalate from sulfatic liquors and also suggests a possible route for further processing of the products with increased marketability. The impurities in the resulting oxides are below $3 \%$, whereby a sufficiently high purity of the mixed oxide can be achieved.
\end{abstract}

Keywords: precipitation; lithium-ion battery; oxalic acid; mixed oxalate

\section{Introduction}

Lithium-ion batteries (LIBs) have been available on the market since the early 1990s [1]. Technological innovations driven by various branches of industry have led to a large number and variety of different electronic devices worldwide [2]. These developments have greatly stimulated the production and consumption of LIBs [3]. Due to their desirable characteristics such as reduced size and weight, high cell voltage, low self-discharge rates and high energy density, LIBs are increasingly replacing other types of batteries (e.g., Ni-MH or Ni-Cd batteries) [1,4]. Nevertheless, it must be considered that electronic waste is the fastest growing solid waste problem worldwide, including LIBs for electronic devices and vehicles [5]. For this reason, the recycling of lithium-ion batteries must be addressed, not only from an environmental point of view, but also for its economic benefits due to the increasing price of cobalt [6]. The main valuable metals in LIBs (cobalt, nickel and lithium) were evaluated by the European Union in terms of criticality. Critical raw materials are highlighted and located within their criticality zone of the graph exhibited in Figure $1[7,8]$. For example, nickel has a very high economic importance as an alloying element in advanced stainless steels $[9,10]$, but a significant low supply risk. In contrast, the supply risk for cobalt is considerably higher. Critical raw materials are highlighted and located within the criticality zone of the graph. $[7,8]$ 


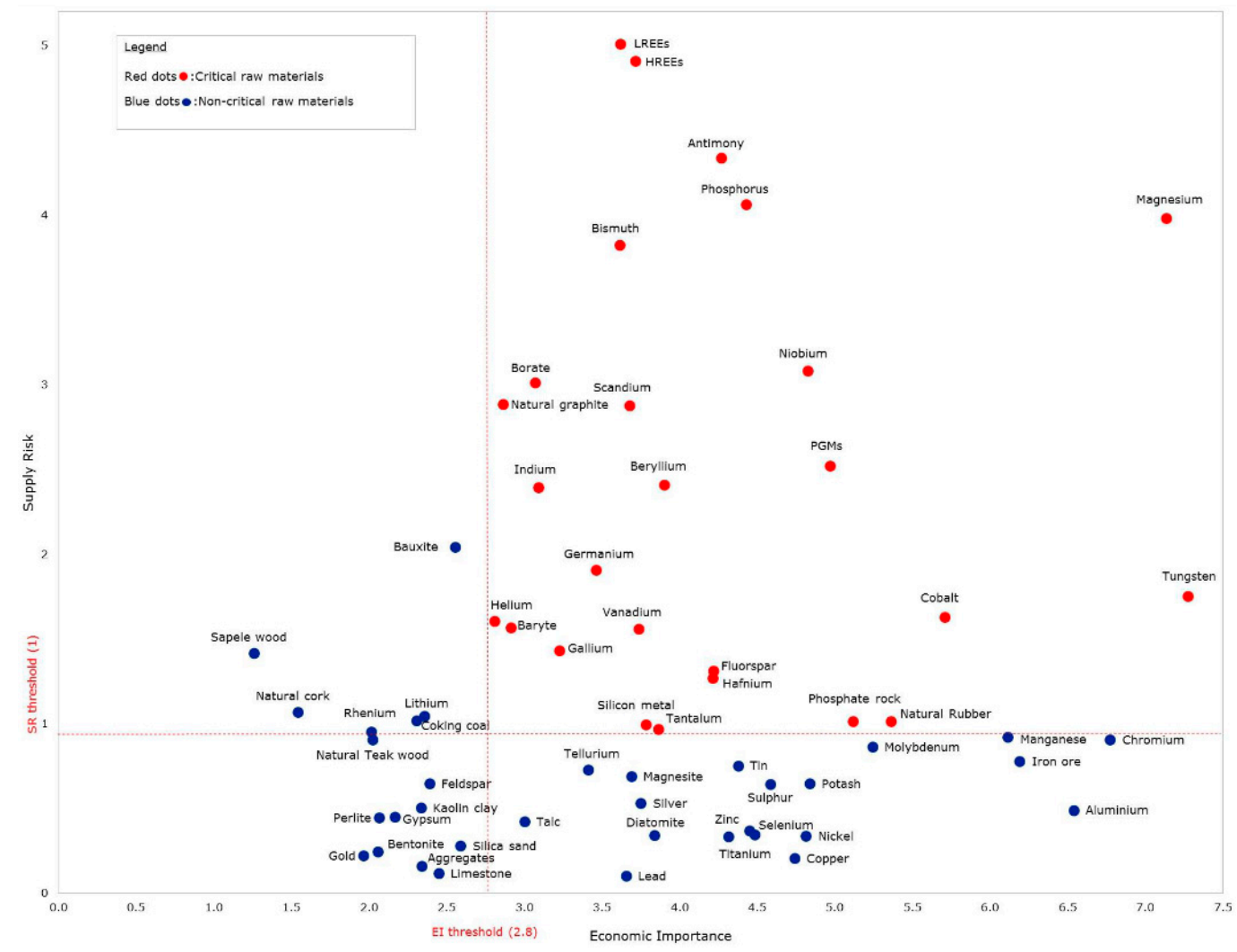

Figure 1. Economic importance and supply risk of raw materials in the European Union 2020 [7].

The analysis of the worldwide supply indicates that cobalt is mined in 19 countries but, as demonstrated in Figure 2, the Democratic Republic of Congo (DRC) represents the most important global supplier with a share of $64 \%$ (based on a five-year average between 2010 and 2014). In Europe, cobalt mining takes place exclusively in New Caledonia (France) and Finland, corresponding to $2 \%$ and $1 \%$ of the global market, respectively. Although this provides a partial independence and a sufficient supply of cobalt as a raw material to the European Union, recycling mechanisms for cobalt are yet to be addressed [7].

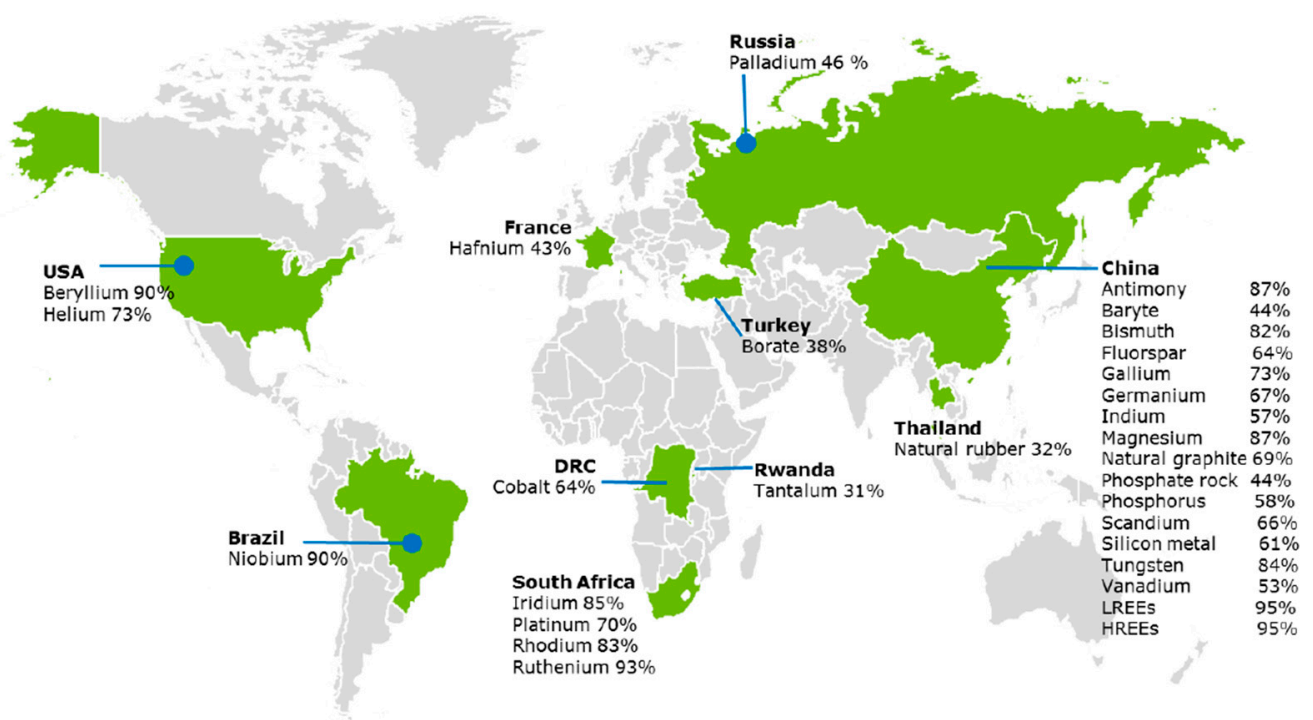

Figure 2. Countries accounting for largest share of the global supply of critical raw materials [7]. 
Spent LIBs usually contain significant amounts of inorganic compounds such as heavy metals as well as organic substances and therefore are classified as hazardous wastes, resulting in stricter worldwide regulations regarding their disposal $[2,4,5]$. The anode of LIBs contains a copper foil coated with graphite (see Figure 3). The cathode consists of an aluminum foil covered with an active material (e.g., lithium cobalt oxide). Due to the presence of valuable metals in LIBs mainly in the active material, the development of efficient recycling technologies is of paramount importance for industry. In addition, the invention of new cathode materials aimed at increasing the efficiency of LIBs will possibly lead to more complicated waste streams and new challenges in the field of recycling. With advanced compositions of active materials, the separation of the contained valuable metals may be even harder, reinforcing the need for the development of innovative recycling technologies [3,5].

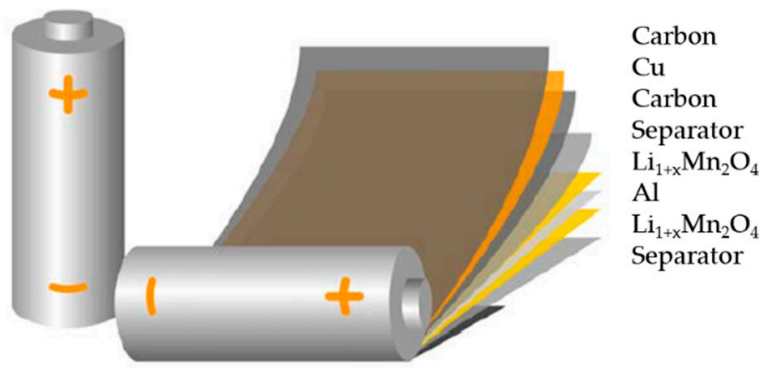

Figure 3. Schematic drawing showing the components of a lithium-ion battery [11].

In principle, pyro- and hydrometallurgical processes are already used for the recycling of LIBs. The pyrometallurgical operations have been used by several companies (such as Inmetco, Umicore and Xstrata), but are currently discouraged due to some disadvantages such as the thermal treatment of binder and organic electrolytes, which is expensive due to high energy requirement, emission of hazardous gases and dust as well as loss of critical metals (e.g., lithium) in the slag $[1,5,6]$.

Hydrometallurgical processes often comprise several stages to allow a clean separation of individual valuable metals. In general, they include dismantling, physical separation, crushing, acid leaching with or without additives as well as numerous separation and purification steps. The segregation of cobalt and nickel is not simple due to their physico-chemical similarities. One attractive possibility to separate these metal ions from acidic leachates comprises solvent extraction, since $\mathrm{Co}$ (II) has a higher tendency to form stable complexes than nickel. However, as this process is complicated and laborious, the research area has been extended to precipitation combinations. Several papers mentioned the use of different precipitants in multi-step processes [2,5,12-14].

The recovery of cobalt and nickel can be accomplished in several ways. Nickel can be selectively precipitated by adding dimethylglyoxime reagent (DMG, $\mathrm{C}_{2} \mathrm{H}_{8} \mathrm{~N}_{2} \mathrm{O}_{2}$ ) to the leach liquor. After the dissolution of the filtered precipitate with hydrochloric acid, the DMG can be regenerated and reused as a precipitant, while nickel is recovered as $\mathrm{NiCl}_{2}$ in the filtrate. This process step depends not only on the temperature but also on the set $\mathrm{pH}$-value. The $\mathrm{pH}$ of the acidic leaching solutions has to be adjusted by adding a base (e.g., $\mathrm{NaOH}$ ) in order to achieve the highest efficiency of the precipitation. The return of dimethylglyoxime to the process cycle is associated with losses (up to approx. $40 \%$ ), since the chemical cannot be completely regenerated. Although high-grade mixed nickel-cobalt precipitates are generated in various processes and are expected to dominate the feed materials used in the next decade for the production of battery-grade nickel and cobalt sulphates [15], due to the high cost of the dimethylglyoxime as a precipitation agent, this method in particular only finds application on a small scale $[1,3,5,16]$.

For the recovery of cobalt, selective precipitation as well as solvent extraction are used. Solvent extraction is used to remove cobalt from liquors that also contain nickel due to reagent costs. This leaves behind a liquor containing nickel [17]. In the course of the precipitation, oxalic acid or ammonium oxalate are applied as reagents. The efficiency of this process highly depends on temperature, with the best results observed around a temperature of $50-55^{\circ} \mathrm{C}$. The $\mathrm{pH}$ also plays a role, although contradictory 
data are found in the literature. The resulting oxalate can be processed into an oxide via a calcination process. Alternatively, ion exchange can be used for the separation of cobalt from the leach solution, in order to subsequently precipitate nickel as an oxalate $[1-5,14]$.

Furthermore, lithium and manganese are often dissolved in these leach solutions, allowing these metals to be removed through several different process steps. In order to extract manganese from solution, either precipitation with potassium permanganate $\left(\mathrm{KMnO}_{4}\right)$ can be implemented or co-extraction via oxalate precipitation can be performed. Lithium can be removed either as a carbonate or phosphate with the addition of precipitants, usually in the last stage of the process $[3,5,18]$.

This work is aimed at testing a hydrometallurgical process to recover nickel and cobalt from sulfuric acid leachates of spent lithium-ion batteries followed by selective precipitation via oxalic acid $\left(\mathrm{C}_{2} \mathrm{H}_{2} \mathrm{O}_{4}\right)$. The recycling process proposed in this work is then optimized by identifying and adapting relevant processing parameters.

\section{Materials and Methods}

\subsection{Composition of the Input Material}

The used active material from lithium-ion batteries was obtained from NMC cells with low levels of other metal impurities. The main components were cobalt, nickel, manganese and lithium, along with small residual amounts of the copper and aluminum foils. The composition was determined by inductively coupled plasma mass spectrometry (ICP-MS, Agilent 8800, Santa Clara, CA, United States) with an upstream peroxide digestion, as shown in Table 1. The carbon contained was pre-determined by an analysis of the total carbon content, and the ICP-MS data were adjusted accordingly on the basis of these results.

Table 1. Chemical composition of the material used in this work.

\begin{tabular}{lcccccccccc}
\hline Element & $\mathbf{C}$ & $\mathbf{A l}$ & $\mathbf{C o}$ & $\mathbf{F e}$ & $\mathbf{L i}$ & $\mathbf{M g}$ & $\mathbf{M n}$ & $\mathbf{N i}$ & $\mathbf{S i}$ & $\mathbf{C u}$ \\
\hline$(\mathrm{wt} \%)$ & 38.7 & 3.4 & 15.0 & 0.4 & 4.0 & 0.1 & 0.8 & 17.0 & $<1.0$ & 3.7 \\
\hline
\end{tabular}

\subsection{Experimental Procedure}

The first stage of work aimed for the optimization of the leaching process. In this study, the main parameters of this method were investigated (using the experiment setup shown in Figure 4). At a given concentration of the acid (1-2 mol/L), the optimal parameter combination comprises $80{ }^{\circ} \mathrm{C}, 100 \mathrm{~g} / \mathrm{L}$ solids, magnetic stirrer speed $\left(500 \mathrm{~min}^{-1}\right)$ and $4 \mathrm{~h}$ of leaching time $[19,20]$. The acid concentration was found within this low range to result in higher selectivity of the leaching. These specific parameters prevented copper from being dissolved and, as a result, this contaminant can be separated in the first step [21].

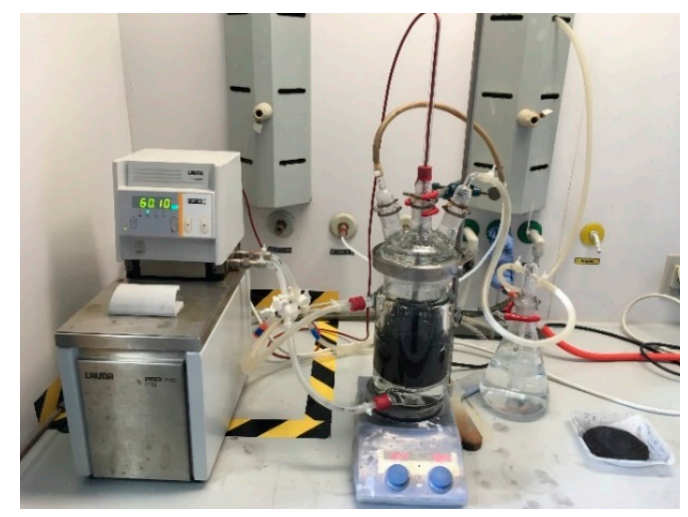

Figure 4. Setup of the leaching process under optimized conditions in the laboratory (double walled reaction vessel with a reaction volume of one liter and a thermostat to control the chosen process temperature). 
After leaching, selective precipitation of the valuable metals cobalt and nickel was conducted to generate a high quality product. Since almost no appropriate thermodynamic data are available in the literature for these concentrated metal-containing solutions and their precipitates such as mixed oxalates, the equilibrium concentration of the metals could not be calculated. In addition, the interactions between the metals in solution have not been determined. For this purpose, an optimization of the relevant parameters of precipitation with oxalic acid takes place in the context of this work. The yield of a pure cobalt-nickel mixed oxalate from the leaching solution was targeted. The parameters optimized were the stoichiometric factor of oxalic acid addition, the adjusted $\mathrm{pH}$ value and the retention time during the precipitation (see Table 2). The $\mathrm{pH}$ was adjusted before the start of the precipitation process and thus before the addition of the precipitant at room temperature by adding sodium hydroxide solution. The measurement was carried out using a pH meter (InLab Science, Mettler-Toledo, Vienna). The stoichiometric amount of precipitant was calculated based on the concentration of the valuable metals in the leaching solution, which was determined via ICP-MS. The temperature was set at $55^{\circ} \mathrm{C}$ for these experiments based on previous work $[4,21]$. This approach should result in identification of the main influencing factors and a detection of the dependencies on each parameter. After conducting the experiments, the filtrates were analyzed by ICP-MS, while the solids were characterized by SEM/EDS (Scanning Electron Microscopy with Energy Dispersive Spectroscopy). The results were evaluated with the help of a statistical experimental design software (MODDE 12.1, Goettingen, Germany). At this stage of research, the test parameters were screened using a full factorial experimental design to enable evaluation of a linear model that considers the interaction of the factors.

Table 2. Parameters of the executed experiments.

\begin{tabular}{cccc}
\hline Experiment & Stoichiometric Addition of Oxalic Acid & $\mathbf{p H}$ & Retention Time (h) \\
\hline F1 & $1.5 \times$ & 0 & 4 \\
F2 & $2 \times$ & 0 & 4 \\
F3 & $1.5 \times$ & 1 & 4 \\
F4 & $2 \times$ & 1 & 4 \\
F5 & $1.5 \times$ & 2 & 4 \\
F6 & $2 \times$ & 2 & 4 \\
F7 & $1.5 \times$ & 0 & 8 \\
F8 & $2 \times$ & 0 & 8 \\
F9 & $1.5 \times$ & 1 & 8 \\
F10 & $2 \times$ & 1 & 8 \\
F11 & 1.5 & 2 & 8 \\
F12 & 2 & 2 & 8 \\
\hline
\end{tabular}

\section{Results}

In the course of the precipitation test work, several parameters (duration of precipitation, $\mathrm{pH}$ value and the added amount of precipitant) were varied and their overall influence on the process was evaluated. Table 3 shows the concentrations of metals contained in the leaching solution. These concentrations were determined by ICP-MS and thus enable the calculation of the corresponding yields of recovered fractions after the precipitation process.

Table 3. Concentrations of the metals in the leaching liquor, which was used for the subsequent precipitation tests.

\begin{tabular}{ccccccc}
\hline $\mathrm{Li}(\mathrm{g} / \mathrm{L})$ & $\mathrm{Al}(\mathrm{g} / \mathrm{L})$ & $\mathrm{Mn}(\mathrm{g} / \mathrm{L})$ & $\mathrm{Fe}(\mathrm{g} / \mathrm{L})$ & $\mathrm{Mg}(\mathrm{g} / \mathrm{L})$ & $\mathrm{Co}(\mathrm{g} / \mathrm{L})$ & $\mathrm{Ni}(\mathrm{g} / \mathrm{L})$ \\
\hline 4.1 & 2.1 & 0.7 & 0.3 & 0.1 & 12.7 & 13.3 \\
\hline
\end{tabular}




\subsection{Influence of the Retention Time}

For this series of experiments, the holding periods after addition of the precipitant were set to between four and eight hours based on a preliminary test. During the tests, the precipitation solution was stirred uniformly by using a magnetic stir plate at a speed of $500 \mathrm{~min}^{-1}$ to ensure efficient mixing. The experiments F1-F6 represent those with a retention time of four hours. In comparison, the experiments F7-F12 describe tests with an $8 \mathrm{~h}$ retention time. Figure 5 shows the composition of the filtrates obtained through precipitation with oxalic acid after the stated holding periods. In order to make it possible to use the obtained product as a recycled battery material, the concentration of impurities in the precipitate must be low, due to the high quality demands of battery manufacturers. Therefore, all impurity elements, such as magnesium, should be located in the filtrate after this precipitation stage.

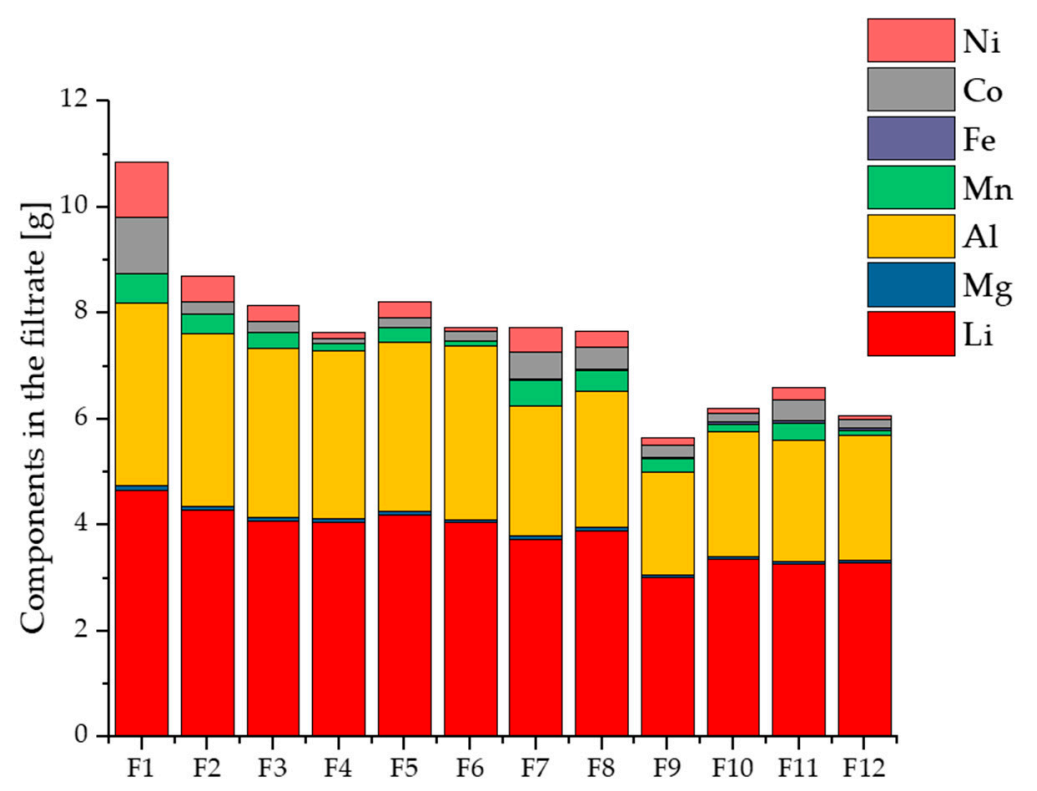

Figure 5. Compositions of the filtrate after precipitation with oxalic acid.

For the evaluation of the experiments, special emphasis was given to the residual cobalt and nickel contents in the filtrates. The content of valuable metals in the solutions should be as low as possible, while the precipitate should contain low levels of impurities. Higher contents in the filtrate indicate poor precipitation and thus lead to a lower yield in the corresponding filter cake. The results for the valuable metals cobalt and nickel are indicated separately in Figure 6. Experiment F1 shows very high residual cobalt and nickel contents compared to the other tests. Since there were no other changes to the parameters for F2, only the amount of precipitant added can be decisive. However, since the further experiments (e.g., F7) show that the used 1.5× stoichiometric amount of oxalic acid sufficed for an efficient precipitation, experiment F1 was excluded from the following considerations due to the result of a statistical evaluation (the corresponding measured value is outside four times the standard deviation). 


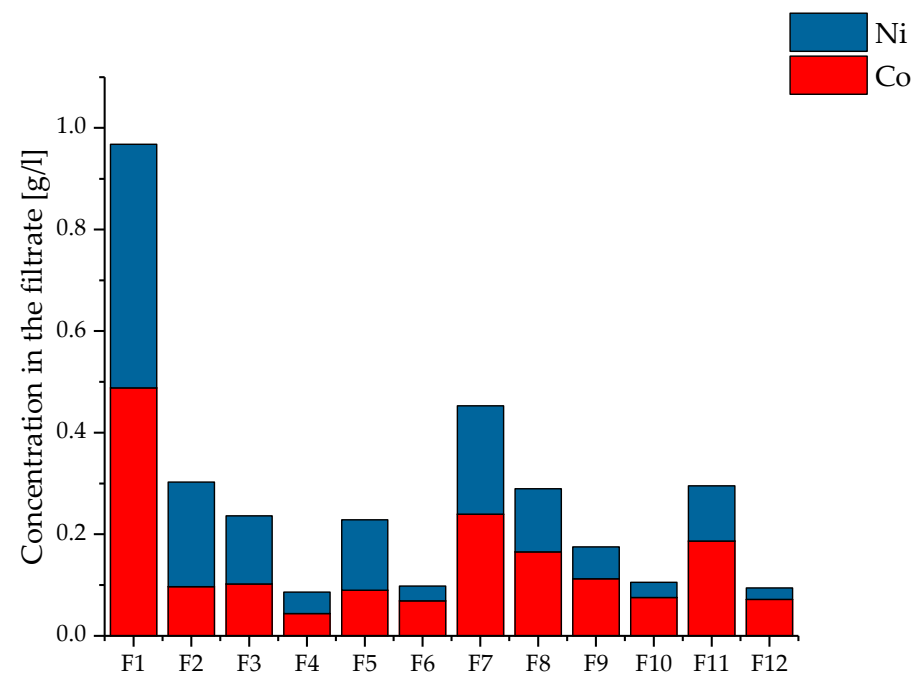

Figure 6. Concentration of cobalt and nickel in the filtrate after precipitation with oxalic acid.

The comparison of the four-hour tests with the corresponding eight-hour tests (with otherwise the same parameters) shows that an extension of the precipitation time is of minor advantage. The residual contents are in a very low range and in all cases considered, the results of the four-hour experiments are the same or better than that with longer test periods except for the comparison of experiments F1 and F7. In general, the residual cobalt contents after eight hours exhibit higher values than after four hours in contrast to the behavior of nickel. This can be traced back to the redissolution of Co (see Figure 7). In this diagram, the solid lines indicate the upper and lower confidence intervals, while the dashed line reflects the predicted values according to the model used for this evaluation. To create these diagrams, a full factorial model was used and its factors were fitted statistically to the experimental results. This resulted in the following model equation for cobalt and nickel, where $x$ indicates the stoichiometric factor (-) of precipitant, $\mathrm{pH}(-)$ is the $\mathrm{pH}$ value, and $\mathrm{t}(\mathrm{h})$ is the precipitation time of the process.

$$
\begin{gathered}
c_{C_{0}}=0.303-0.754 * x_{\text {Oxalic acid }}-0.348 * p H+0.028 * t+0.162 * x_{\text {Oxalic acid }} * p H \\
c_{N i}=0.330-0.443 * x_{\text {Oxalic acid }}-0.073 * p H-0.025 * t
\end{gathered}
$$
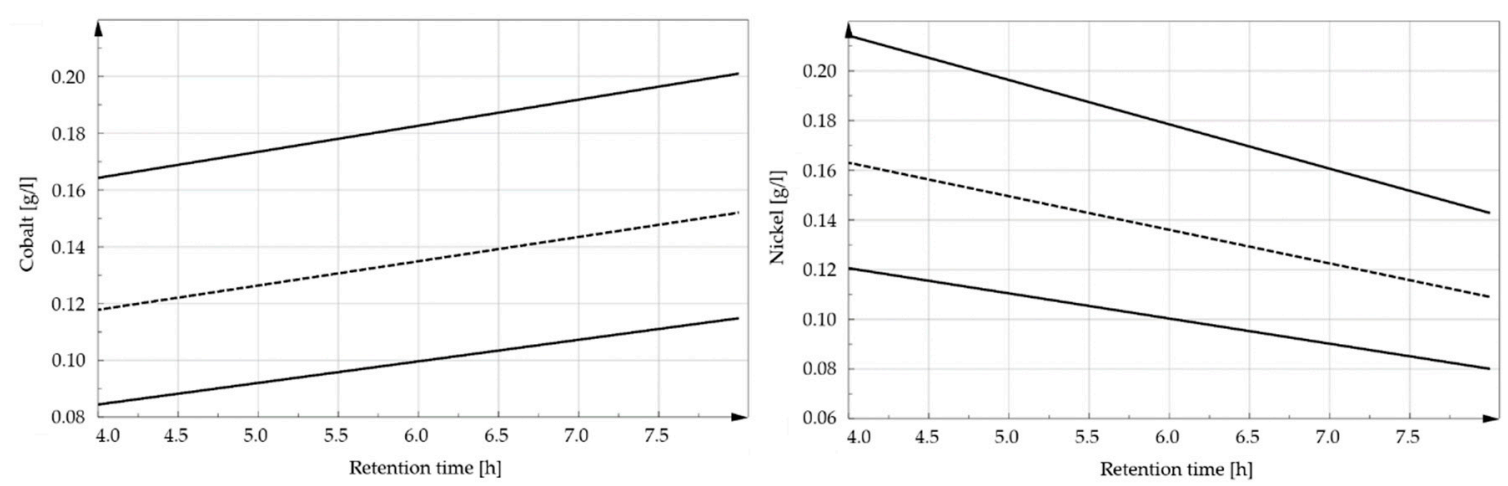

Figure 7. Behavior of soluble cobalt and nickel as a function of retention time (solid lines indicate the upper and lower confidence intervals, while the dashed line reflects the predicted values according to the model). 
These tendencies could not have been foreseen because, as mentioned earlier, the compounds of these two valuable metals often show similar behavior. This behavior can be explained by the mutual influence of the components in the concentrated solution in dependence of the concentrations of cobalt and nickel regarding their solubility (salt effect). Much of the data available in the literature relate exclusively to dilute solutions of single metals, and interactions between different metals are often neglected. Therefore, further investigations must be carried out for concentrated solutions, not only of pure substances but also mixtures containing two or more metals and their behavior.

This effect, shown in Figure 7, is less pronounced at higher $\mathrm{pH}$ values than at lower ones. The same applies to the dependence on the amount of precipitant added. In order to expand this model further, additional tests were carried out, up to a $\mathrm{pH}$ value of 4 , which was set before the precipitation process. The analysis of the residual dissolved concentrations in the filtrate yielded the results shown in Figure 8 . From an economic perspective, use of a precipitation period of four hours instead of eight is sufficient for the efficient precipitation of cobalt and nickel with oxalic acid from the enriched solutions with recovery yields above $95 \%$. However, tests to further reduce the holding period should be carried out in order to define the critical precipitation time more precisely. In the following diagrams, the residual concentrations of cobalt and nickel in the filtrate are plotted in $\mathrm{g} / \mathrm{L}$.
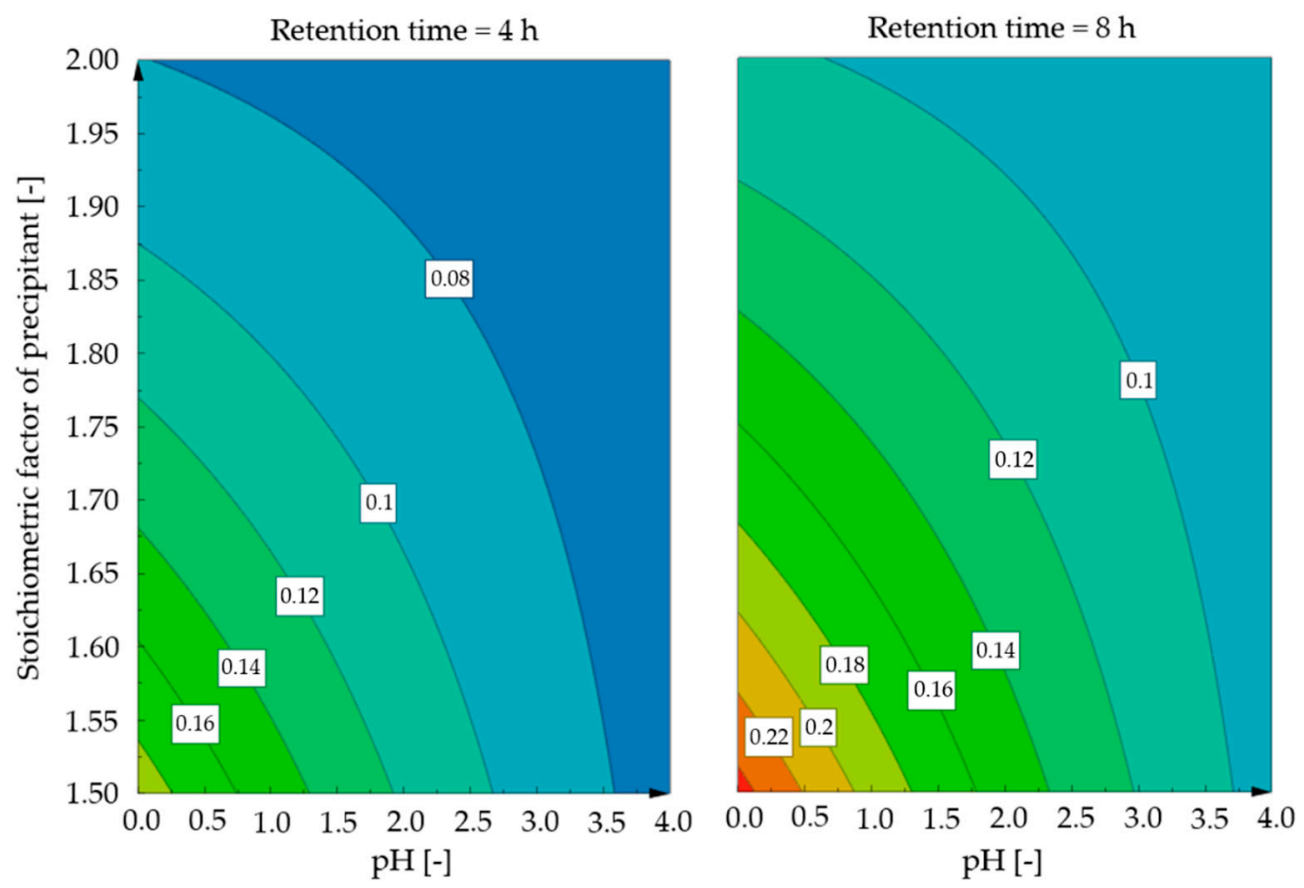

Figure 8. Statistical evaluation of the residual dissolved concentrations $(\mathrm{g} / \mathrm{L})$ of cobalt for 4 and $8 \mathrm{~h}$ retention time, respectively.

The strong influence of the $\mathrm{pH}$ value can be seen in Figure 8, since at high acid concentrations, twice as much cobalt remains in the residual solution as at $\mathrm{pH}$ values above 3.5. Furthermore, the excess of precipitation agent only plays an increasingly significant role as the $\mathrm{pH}$ value decreases, irrespective of the retention time.

Dependencies are different for nickel because of linear relations without interaction parameters. As shown in Figure 9, twice the residual nickel concentrations are obtained with a reduction from eight to four hours with a small stoichiometric addition of precipitant. This effect is significantly reduced at higher oxalic acid levels or higher $\mathrm{pH}$ values. In the case of nickel, minimal residual levels occur for a precipitation time of eight hours, and at a $\mathrm{pH}$ value of 4 , no nickel could be detected in the residual solution. 

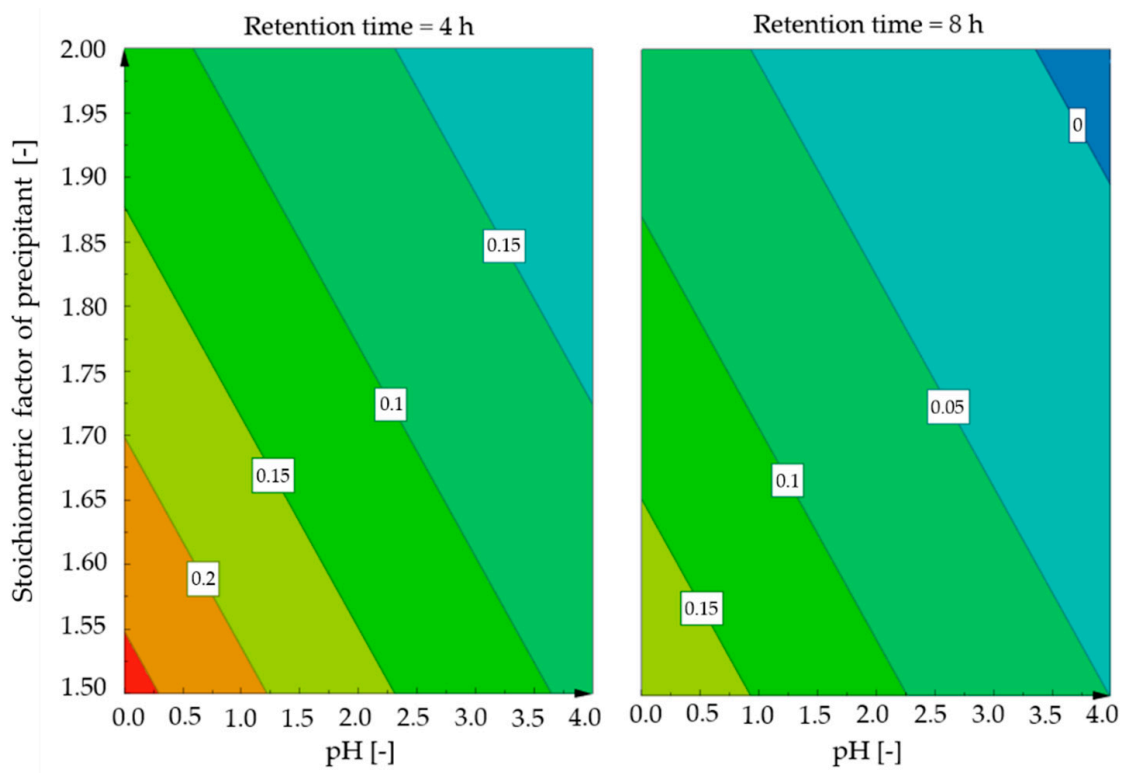

Figure 9. Statistical evaluation of the residual dissolved concentrations $(\mathrm{g} / \mathrm{L})$ of nickel for 4 and $8 \mathrm{~h}$ retention time, respectively.

\subsection{Influence of the $\mathrm{pH}$ Value}

An examination regarding the higher-priced valuable cobalt shows that at elevated $\mathrm{pH}$ values, lower residual contents are expected in the solution. From a $\mathrm{pH}$ value of $3-3.5$, there is no further improvement in the precipitation efficiency. Furthermore, a direct dependency on the amount of precipitant added can no longer be recognized above this $\mathrm{pH}$ value, since even a smaller amount of oxalic acid leads to the maximum possible precipitation yield. It was also shown that no selective precipitation of cobalt or nickel is possible over the entire $\mathrm{pH}$ range tested, but that a mixed oxalate was always obtained. The comparison of the minimum and maximum $\mathrm{pH}$ value indicates a doubling of the cobalt content in the residual solution at low $\mathrm{pH}$ values and low amounts of precipitant. This effect can no longer be observed with an efficient oxalic acid supply. In order to visualize the combined dependency on the $\mathrm{pH}$ value and stoichiometrical factor of oxalic acid, the trends are shown in Figure 10.

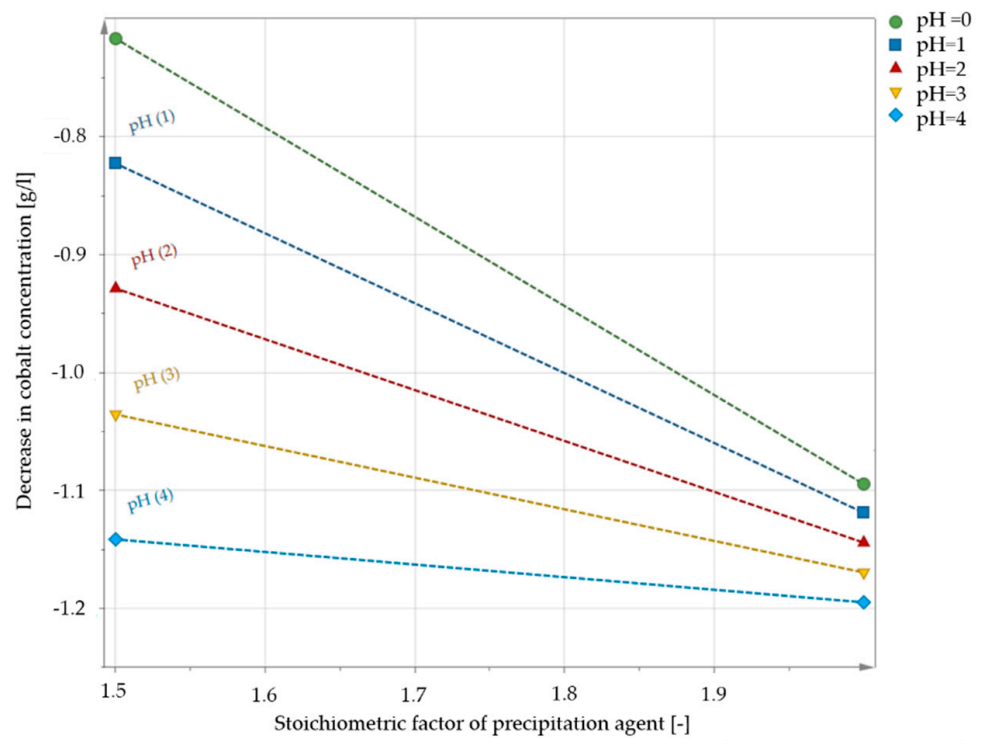

Figure 10. Influence of the $\mathrm{pH}$ on the difference of cobalt concentration between the stoichiometric addition of 1.5 and 2.0. 
In general, for both cobalt and nickel, it turns out that a higher stoichiometric factor for oxalic acid leads to a lower influence of the $\mathrm{pH}$ value. This fact is presented in Figure 11. The areas marked indicate the parameter combination with the highest precipitation efficiency. However, the parametric region for an efficient recovery of cobalt (shown in blue) significantly exceeds that for nickel.
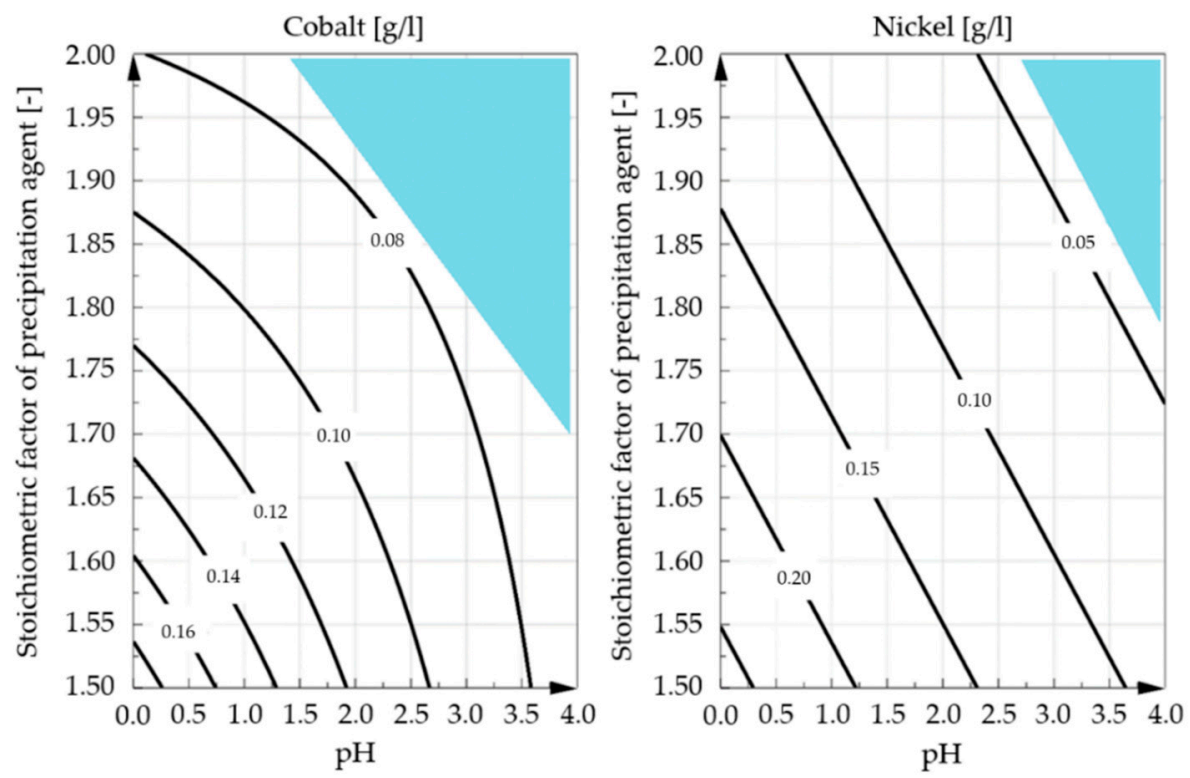

Figure 11. Influence of $\mathrm{pH}$ on the residual dissolved concentrations of cobalt and nickel.

\subsection{Influence of the Added Amount of Precipitant}

To ensure the effectiveness of the precipitation, it is important that sufficient precipitation reagent is dosed to generate a high yield of precipitated valuable metals. In contrast, economic and resource-saving approaches have to be considered. For this reason, the stoichiometric factor of precipitant that enables an improvement of the process performance was evaluated. The tested range was set between 1.5 and 2 times the theoretically required stoichiometric amount of oxalic acid. All experiments showed that an addition of the lower value of precipitant sufficed to precipitate the majority of valuable metals. The addition of higher amounts led to only a slight improvement of the yields and therefore makes little sense economically and environmentally. Nevertheless, it has previously been discussed that the dependencies of precipitation on $\mathrm{pH}$ value and duration were more pronounced with smaller amounts of oxalic acid added than with higher ones. Figure 12 shows the influence of oxalic acid on the levels of cobalt and nickel in the residual solution. In this figure, the solid lines indicate the upper and lower confidence intervals, while the dashed line reflects the predicted values according to the model. In future investigations, a reduction in the amount added should be tested in order to determine the minimum needed amount of precipitant. 

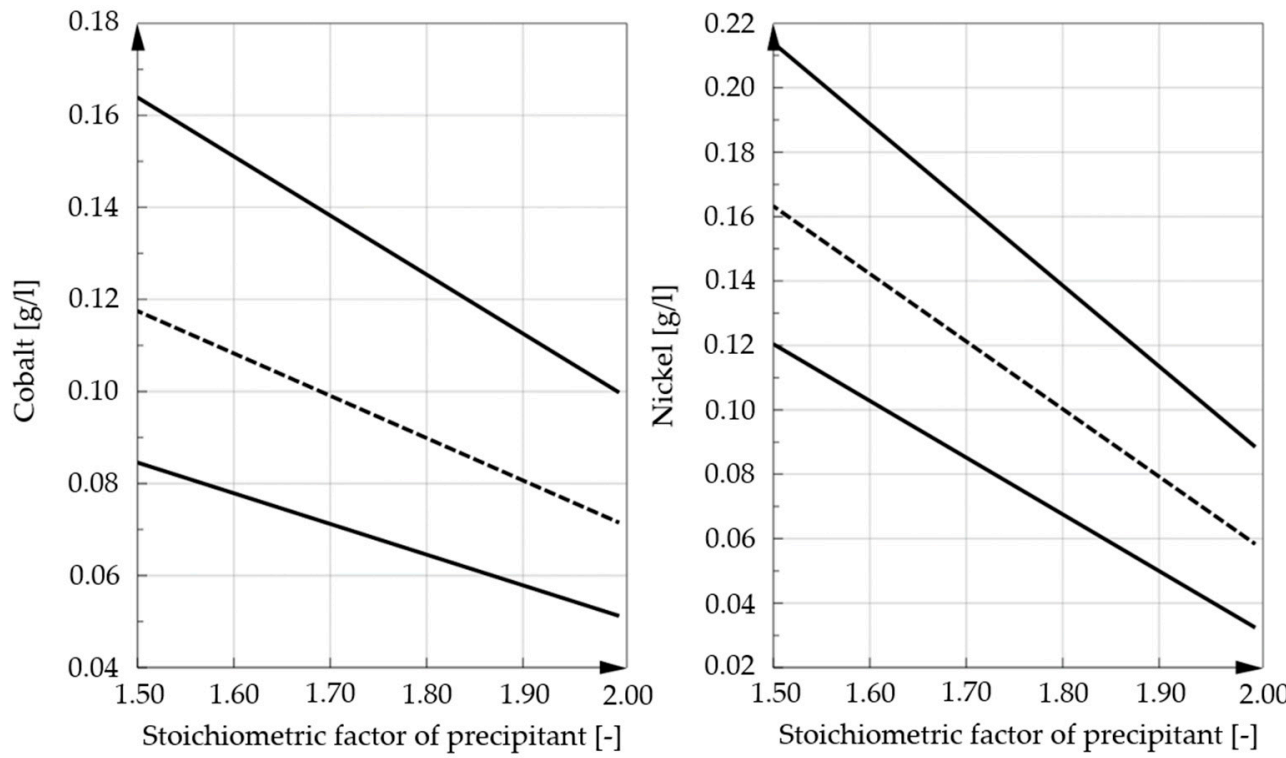

Figure 12. Dependence of residual cobalt and nickel concentrations on the stoichiometric amount of precipitation agent added for a fixed $\mathrm{pH}$ of 2 and a precipitation time of four hours (solid lines indicate the upper and lower confidence intervals, while the dashed line reflects the predicted values according to the model).

\subsection{Composition of the Obtained Product}

The precipitate obtained (mixed cobalt-nickel oxalate) was separated from the filtrate by means of vacuum filtration and rinsed with $200 \mathrm{~mL}$ of boiling, deionized water in order to remove impurities such as sulfates. After drying for $24 \mathrm{~h}$ at $105^{\circ} \mathrm{C}$ in a drying oven, a semi-quantitative analysis was carried out by scanning electron microscopy and energy dispersive X-ray spectroscopy (Jeol Ltd., Tokyo, Japan) (SEM/EDS). Table 4 indicates the corresponding metal contents normalized to $100 \%$ for selected elements, given that lithium cannot be detected using EDS by the available device at our institute. It can be observed that the levels of impurities are low. In addition, no copper could be detected in the precipitate, which is a relevant feature for further processing of the product and later use in various industries (e.g., stainless steel industry). On the basis of the data obtained from the software of the EDS measurement, no significant amount of copper could be detected, which could be clearly separated from the background noise of the measurement. Since this analysis method only outputs reproducible values to a limited extent, because of the detection limits of EDS and also the possibly existing inhomogeneity in the sample, especially in the case of low contents, ICP-AES analysis is planned for future studies to specifically analyze minor elements such as $\mathrm{Cu}, \mathrm{Al}, \mathrm{Mn}$ and $\mathrm{Fe}$.

Table 4. Metal contents of the obtained mixed cobalt-nickel oxalates.

\begin{tabular}{cccccccccc}
\hline No. & $\begin{array}{c}\text { Oxalic } \\
\text { Acid }\end{array}$ & $\mathbf{p H}$ & $\begin{array}{c}\text { Retention } \\
\text { Time (h) }\end{array}$ & $\begin{array}{c}\mathbf{C o} \\
\mathbf{( w t} \%)\end{array}$ & $\begin{array}{c}\mathbf{N i} \\
\mathbf{( w t} \%)\end{array}$ & $\begin{array}{c}\mathbf{C u} \\
(\mathbf{w t} \%)\end{array}$ & $\begin{array}{c}\mathbf{A l} \\
(\mathbf{w t} \%)\end{array}$ & $\begin{array}{c}\mathbf{M n} \\
(\mathbf{w t} \%)\end{array}$ & $\begin{array}{c}\mathbf{F e} \\
(\mathbf{w t} \%)\end{array}$ \\
\hline 1 & $1.5 \times$ & 0 & 4 & 45.7 & 50.5 & 0.0 & 1.3 & 1.0 & 1.5 \\
2 & $2 \times$ & 0 & 4 & 45.2 & 51.2 & 0.0 & 1.1 & 1.5 & 1.1 \\
3 & $1.5 \times$ & 1 & 4 & 46.2 & 50.5 & 0.0 & 1.0 & 1.4 & 0.9 \\
4 & $2 \times$ & 1 & 4 & 46.0 & 50.3 & 0.0 & 0.9 & 1.8 & 1.0 \\
5 & $1.5 \times$ & 2 & 4 & 46.8 & 49.4 & 0.0 & 1.1 & 1.4 & 1.3 \\
6 & $2 \times$ & 2 & 4 & 46.7 & 50.5 & 0.0 & 0.8 & 2.1 & 0.0 \\
7 & $1.5 \times$ & 0 & 8 & 45.1 & 51.7 & 0.0 & 1.2 & 1.2 & 0.8 \\
8 & $2 \times$ & 0 & 8 & 44.8 & 51.4 & 0.0 & 1.2 & 1.6 & 1.0 \\
9 & $1.5 \times$ & 1 & 8 & 46.9 & 49.6 & 0.0 & 1.0 & 1.4 & 1.1 \\
10 & $2 \times$ & 1 & 8 & 46.3 & 50.7 & 0.0 & 1.0 & 2.1 & 0.0 \\
\hline
\end{tabular}


An examination of the data in Table 4 indicates that the sum of the impurities reaches a maximum of $3.8 \%$. These amounts of contaminants correspond to a sufficient high quality of the recycled product, especially as an intermediate that can be used in several industries (e.g., stainless steel industry), as well as a precursor for generation of battery quality materials. In addition, it can be seen that with higher quantities of precipitants, slightly increased contents of impurities in the precipitate also occur due to the more aggressive conditions during the precipitation process. In order to make it possible to use it as a recycled battery material, the quality still needs improvements. In order to separate the existing impurities and obtain a high-quality product, further research is necessary. The precipitate obtained is shown in Figure 13. In addition to the overview picture, the distribution images of the valuable metals and their impurities are also shown.

\section{Overview picture}

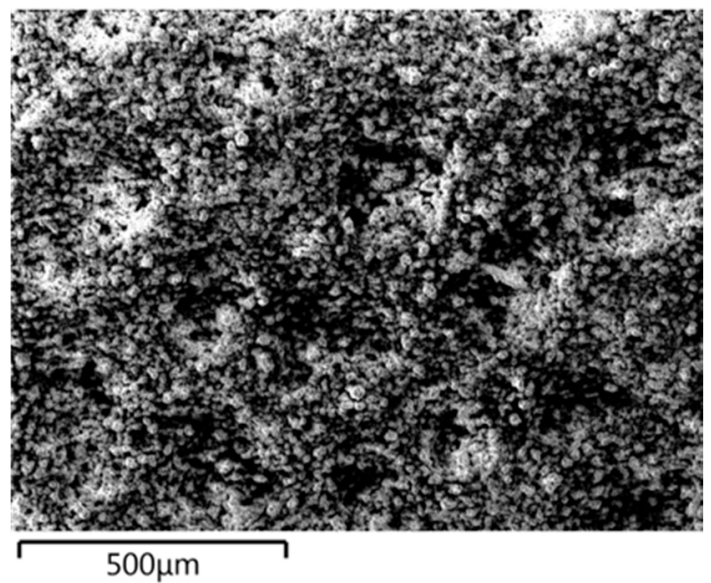

Distribution of nickel

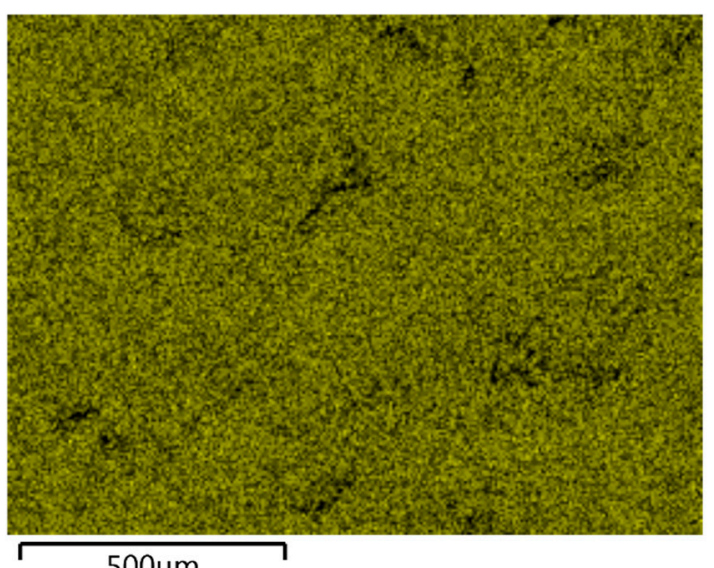

$500 \mu \mathrm{m}$
Distribution of cobalt

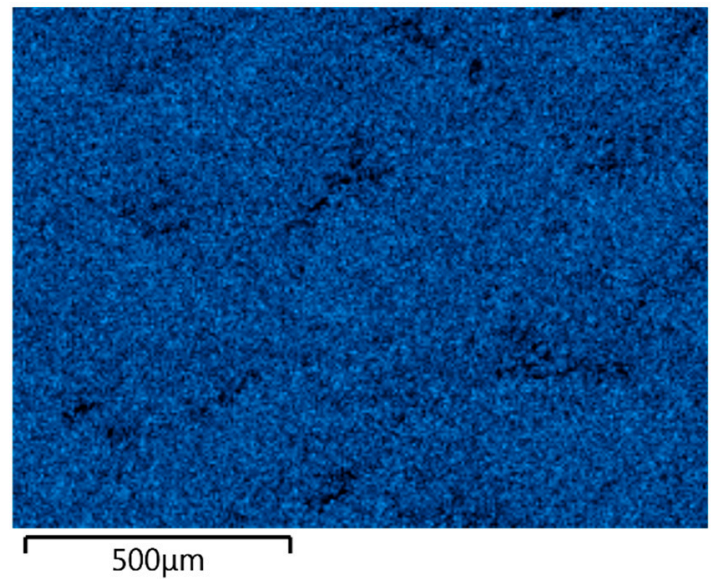

Distribution of manganese

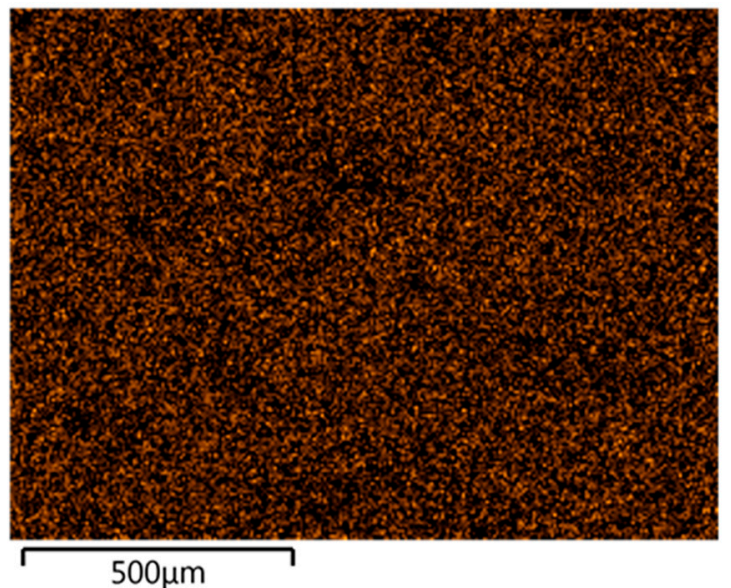

Figure 13. SEM/EDS images of the obtained precipitate.

Figure 13 illustrates that a homogeneous distribution of the metals such as cobalt and nickel and thus a homogeneous mixed product was achieved. Essentially, no segregation of the individual oxalates and thus no major inhomogeneity can be recognized at this magnification. This statement can also be made for manganese and iron, with aluminum accumulations being found in certain areas. However, reference should be made to the generally very low concentration of aluminum in the product. The precipitate can be used as a high-quality raw material for various cobalt and nickel processing industries, with further processing into oxide or alloy being possible [21]. 


\section{Discussion}

The investigations performed in this work demonstrated that various parameters can influence the precipitation of metals when oxalic acid is used in the recycling processes. Small amounts of oxalic acid were observed to induce significant dependencies of precipitation efficiency on $\mathrm{pH}$ and holding period. These tendencies were much less pronounced for higher amounts of precipitant addition. These descriptions apply in principle to both valuable metals (cobalt and nickel), although competing behavior of the two metals could be determined during the evaluation of the test data, since, for example, precipitation times of more than four hours lead to a decrease in the nickel concentration in the solution, while the concentration of cobalt increased again slowly over time and a redissolution process occurred. Since the interdependencies between nickel and cobalt precipitation are difficult to describe, they are represented diagrammatically in Figure 14.
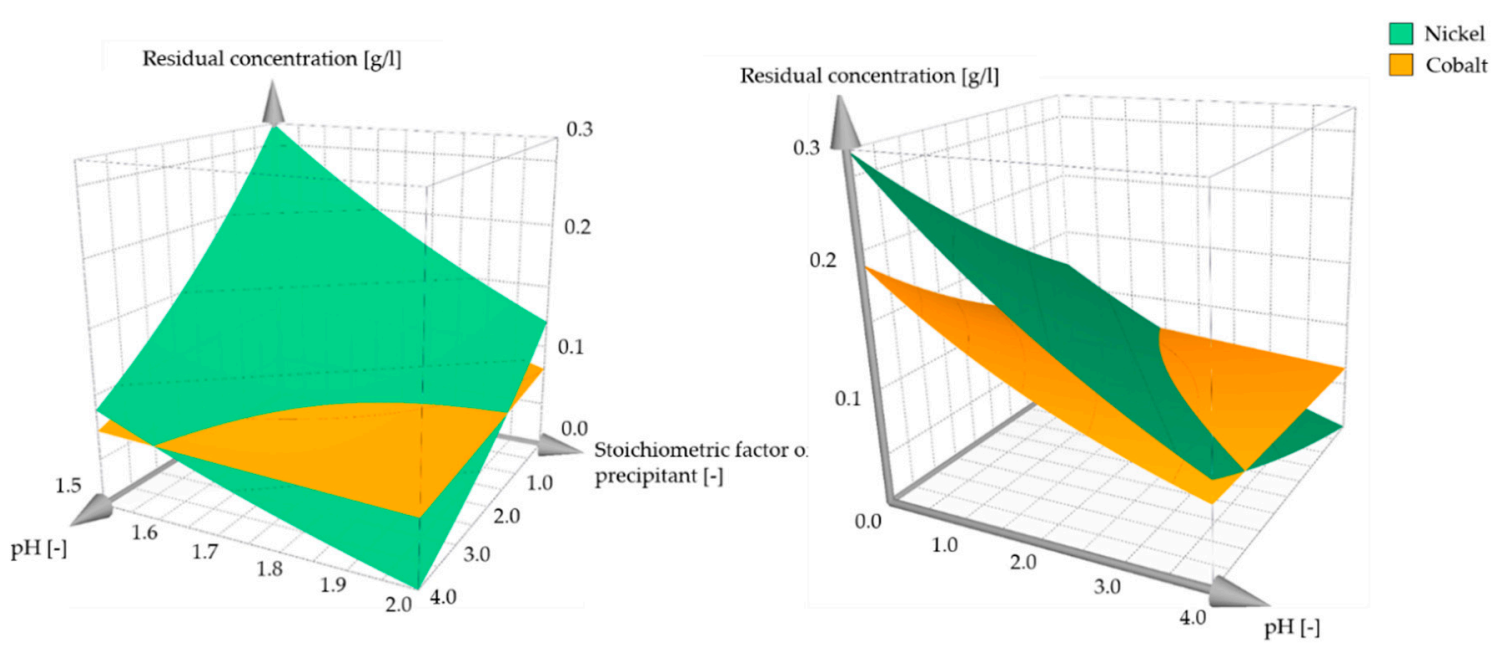

Figure 14. Surface plots for cobalt and nickel precipitation as oxalates and their dependency on the $\mathrm{pH}$ value and the stoichiometric factor of oxalic acid addition.

\section{Conclusions and Outlook}

Oxalic acid is an effective precipitant for the simultaneous recovery of cobalt and nickel from leaching solutions generated from the recycling of lithium-ion batteries. However, it was found that the effectiveness of this organic precipitant has various dependencies on different parameters, which must be taken into account during the precipitation process

In general, smaller amounts of precipitation reagent results in significantly stronger dependencies on $\mathrm{pH}$ and duration of precipitation. As redissolution of cobalt oxalate occurs, the holding time must be limited to a maximum of four hours in order to minimize losses.

Based on the promising results so far, this holding time could be further reduced. The $\mathrm{pH}$ value plays an essential role, since the adaptation is often difficult due to buffer effects.

It was shown that an increase in the $\mathrm{pH}$ of the leach solutions was necessary, with acceptable results achieved at a $\mathrm{pH}$ of 1.5-2. Using this optimized combination of parameters, low levels of cobalt and nickel in the residual solutions and homogenous, sufficient pure products can be obtained.

By determining the competing behaviors of cobalt and nickel depending on the duration of the precipitation process with oxalic acid, further studies of this behavior should be carried out in order to study a potentially new separation mechanism for cobalt and nickel.

Author Contributions: E.G. developed the theoretical formalism, performed the analytic calculations and performed thermodynamical simulations. Both S.L. and H.A. contributed to the final version of the manuscript and supervised the project. All authors have read and agreed to the published version of the manuscript.

Funding: This research was funded by the Austrian Federal Ministry of Science, Research and Economy and the National Foundation for Research, Technology and Development. 
Acknowledgments: The financial support by the Austrian Federal Ministry of Science, Research and Economy and the National Foundation for Research, Technology and Development and the support from the industry by A. Arnberger is gratefully acknowledged.

Conflicts of Interest: The authors declare no conflict of interest.

\section{References}

1. Chen, X.; Zhou, T.; Kong, J.; Fang, H.; Chen, Y. Separation and recovery of metal values from leach liquor of waste lithium nickel cobalt manganese oxide based cathodes. Sep. Purif. Technol. 2015, 141, 76-83. [CrossRef]

2. Fernandes, A.; Afonso, J.C.; Dutra, A.J.B. Separation of nickel(II), cobalt (II) and lanthanides from spent $\mathrm{Ni}-\mathrm{MH}$ batteries by hydrochloric acid leaching, solvent extraction and precipitation. Hydrometallurgy 2013, 133, 37-43. [CrossRef]

3. Chen, X.; Chen, Y.; Zhou, T.; Liu, D.; Hu, H.; Fan, S. Hydrometallurgical recovery of metal values from sulphuric acid leaching liquor of spent lithium-ion batteries. Waste Manag. 2015, 38, 349-356. [CrossRef] [PubMed]

4. Kang, J.; Sohn, J.; Chang, H.; Senanayake, G.; Shin, S.M. Preparation of cobalt oxide from concentrated material of spent lithium ion batteries by hydrometallurgical method. Adv. Powder Technol. 2010, 21, 175-179. [CrossRef]

5. Sattar, R.; Ilyas, S.; Bhatti, H.N.; Ghaffar, A. Resource recovery of critically-rare metals by hydrometallurgical recycling of spent lithium ion batteries. Sep. Purif. Technol. 2019, 209, 725-733. [CrossRef]

6. Golmohammadzadeh, R.; Rashchi, F.; Vahidi, E. Recovery of lithium and cobalt from spent lithium-ion batteries using organic acids: Process optimization and kinetic aspects. Waste Manag. 2017, 64, $244-254$. [CrossRef]

7. European Commission. Study on the Review of the List of Critical Raw Materials: Final Report; Publications Office of the European Union: Luxembourg, 2020.

8. Community Research and Development Information Service (CORDIS). Economic Importance and Supply Risk of Raw Materials in the European Union. Available online: https://cordis.europa.eu/docs/results/h2020/ 660/660885_PS/crit-metals.jpg (accessed on 27 October 2020).

9. Arpe, H.-J.; Ullmann, F. (Eds.) Part A6-Ullmann's Encyclopedia of Industrial Chemistry, 5th ed.; Wiley-VCH Verlag GmbH \&. Co. KGaA: Weinheim, Germany, 1991; pp. 293-300.

10. Arpe, H.-J.; Ullmann, F. (Eds.) Part A18-Ullmann's Encyclopedia of Industrial Chemistry, 5th ed.; Wiley-VCH Verlag GmbH \&. Co. KGaA: Weinheim, Germany, 1986; pp. 213-215.

11. Rahimzei, E.; Sann, K.; Vogel, M.; VDE Verband der Elektrotechnik. Kompendium: Li-Ionen-Batterien. 2015. Available online: https://www.dke.de/resource/blob/933404/3d80f2d93602ef58c6e28ade9be093cf/ kompendium-li-ionen-batterien-data.pdf (accessed on 27 October 2020).

12. Takacova, Z.; Dzuro, V.; Havlik, T. Cobalt Precipitation from Leachate Originated from Leaching of Spent Li-ion Batteries Active Mass - Characterization of Inputs, Intermediates and Outputs. World Metall. 2017, 70, 336c343.

13. Ferreira, D.A.; Prados, L.M.; Majuste, D.; Mansur, M.B. Hydrometallurgical separation of aluminium, cobalt, copper and lithium from spent Li-ion batteries. J. Power Sources 2009, 238-246. [CrossRef]

14. Korthauer, R. (Ed.) Handbuch Lithium-Ionen-Batterien; Springer: Berlin/Heidelberg, Germany, 2013.

15. Rath, M.; Behera, L.P.; Dash, B.; Sheik, A.R.; Sanjay, K. Recovery of dimethylglyoxime (DMG) from Ni-DMG complexes. Hydrometallurgy 2018, 176, 229-234. [CrossRef]

16. Habashi, F. Handbook of Extractive Metallurgy; Wiley-VCH: Weinheim, Germany, 1997.

17. Godlewska, L.; Grohol, M. Study on the Review of the List of Critical Raw Materials: Critical Raw Materials Factsheets; Publications Office of the European Union: Luxembourg, 2020.

18. Luidold, S.; Honner, M.; Antrekowitsch, H. Leaching of metal-containing residues from the battery sector; Gerold, E. World Metall. 2019, 5, 267-273.

19. Gerold, E.; Luidold, S.; Scheiber, S.; Honner, M. Synergy effect at the recycling of metal containing waste from the waste industry. Proc. Eur. Metall. Conf. EMC 2019, 2019, 973-982.

20. Gerold, E.; Luidold, S.; Bartelme, C.; Antrekowitsch, H. Pyrometallurgische Aufarbeitung von Zwischenprodukten beim Batterierecycling. In Proceedings, Recycling und Sekundärrohstoffe, Berlin (2-3 March 2020); Thomé-Kozmiensky Verlag GmbH: Neuruppin, Germany, 2020. 
21. Chen, L.; Tang, X.; Zhang, Y.; Li, L.; Zeng, Z.; Zhang, Y. Process for the recovery of cobalt oxalate from spent lithium-ion batteries. Hydrometallurgy 2011, 108, 80-86. [CrossRef]

Publisher's Note: MDPI stays neutral with regard to jurisdictional claims in published maps and institutional affiliations.

(C) 2020 by the authors. Licensee MDPI, Basel, Switzerland. This article is an open access article distributed under the terms and conditions of the Creative Commons Attribution (CC BY) license (http://creativecommons.org/licenses/by/4.0/). 